\title{
Growth and characterization of GaN films on (0001) sapphire substrates by alternate supply of trimethylgallium and $\mathrm{NH}_{3}$
}

\author{
H.Y. Wang a, S.C. Huang a, T.Y. Yan ${ }^{\text {a }}$, J.R. Gong ${ }^{\text {a,* }}$, T.Y. Lin ${ }^{\mathrm{b}}$, Y.F. Chen ${ }^{\mathrm{b}}$ \\ a Department of Materials Science, Feng Chia University, Taichung, Taiwan, ROC \\ ${ }^{\mathrm{b}}$ Department of Physics, National Taiwan University, Taipei, Taiwan, ROC
}

Received 23 February 1998

\begin{abstract}
$\mathrm{GaN}$ films were grown on (0001) sapphire substrates in a temperature range of $500 \sim 950^{\circ} \mathrm{C}$ by exposing the substrates to trimethylgallium (TMG) and $\mathrm{NH}_{3}$ one at a time. High quality $\mathrm{GaN}$ films were achieved at $800 \sim 900^{\circ} \mathrm{C}$ with a thin $\mathrm{GaN}$ buffer layer predeposited at $500^{\circ} \mathrm{C}$. The linewidth of the $(0004)$ double-crystal rocking curve X-ray diffraction (DCXRD) of a $2.0 \mu \mathrm{m}$ thick $\mathrm{GaN}$ film is about $250 \sim 500$ arcsec. Increment in growth temperature over a temperature range of $800 \sim 900^{\circ} \mathrm{C}$ is helpful to suppress the intensity of yellow luminescence and to enhance the luminescence intensity of the near band-to-band emission. Typically, the room temperature photoluminescence intensity ratio of the near band edge emission to the yellow luminescence for an as-grown high quality GaN film is more than one order of magnitude. The best GaN films with superior optical behavior were achieved at $\sim 900^{\circ} \mathrm{C}$ with a V/III ratio of 5000. Photoluminescence measurements of these GaN films at $9 \mathrm{~K}$ show strong and sharp near band-to-band emission with almost no yellow luminescence. (C) 1999 Elsevier Science S.A. All rights reserved.
\end{abstract}

Keywords: GaN films; Sapphire substrates; Trimethylgallium; $\mathrm{NH}_{3}$

\section{Introduction}

Gallium nitride has become one of the most promising wide band-gap semiconductor materials for use in high brightness blue/green light emitting diodes (LEDs) [1] and laser diodes (LDs) [2] which are very important devices for applications in full-color outdoor LED displays and optical storage devices. Several growth techniques, like metal-organic chemical vapor deposition (MOCVD) [3], molecular beam epitaxy (MBE) [4], and hydride vapor phase epitaxy (HVPE) [5], have been utilized for GaN growth. Due to the lack of suitable lattice-matched substrates, most of the GaN materials and related devices were prepared on sapphire substrates. However, the large differences in the lattice constant and thermal expansion coefficient between the $\mathrm{GaN}$ film and the sapphire make it difficult to obtain high quality GaN films. It has been reported in the literature that a dislocation density as high as $10^{8} \sim 10^{10}$

\footnotetext{
* Corresponding author.
}

$\mathrm{cm}^{-2}[6]$ has been observed in the GaN films grown by conventional techniques. Although high brightness blue/green LEDs can be prepared by MOCVD, high growth temperatures up to $1050^{\circ} \mathrm{C}$ are required for high quality materials. Growth temperature as high as $1050^{\circ} \mathrm{C}$ could generate additional issues like high desorption rate of the group III adatoms as well as the corrosion problem in the graphite susceptor. Accordingly, the implementation of low temperature epitaxy on the III-nitride film growth is of great interest.

Previous reports $[7,8]$ show that the sequential supply of metalorganics and hydrides to the substrate is helpful for the preparation of high quality semiconductor thin films at lower temperatures. Heteroepitaxy of GaN thin films by alternate supply of reactants has recently been reported [9]. However, most of the studies focused upon the behavior of saturation growth instead of the material properties. In this paper we report the achievement of high quality GaN films on (0001) sapphire substrates through process optimization by alternate supply of trimethylgallium (TMG) and $\mathrm{NH}_{3}$. 


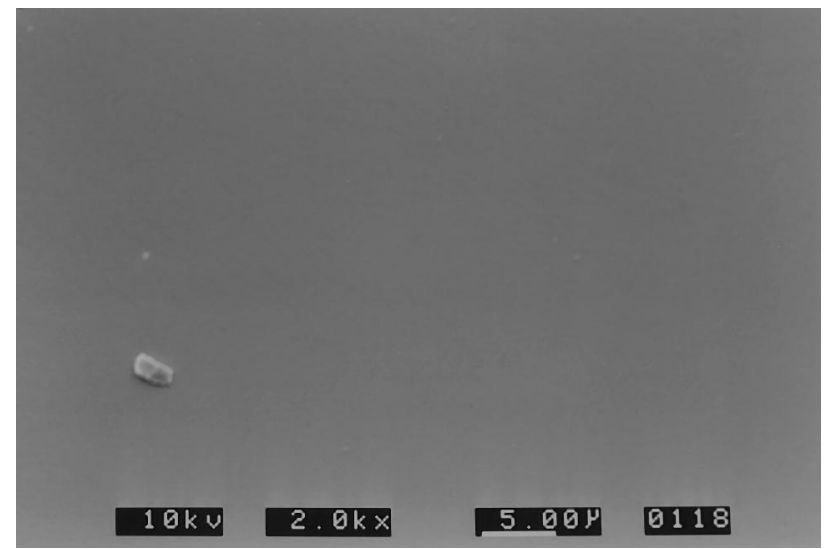

Fig. 1. An SEM micrograph of the surface of a GaN film grown at $800^{\circ} \mathrm{C}$.

\section{Experimental}

Growth of GaN films was carried out in a homemade reactor operated at atmospheric pressure. The reactor and susceptor design is similar to one described previously [8]. TMG and $\mathrm{NH}_{3}$ were used as $\mathrm{Ga}$ and $\mathrm{N}$ sources carried by purified $\mathrm{H}_{2}$ gas. During $\mathrm{GaN}$ growth the sapphire substrate was carried to expose it to the space-separated TMG and $\mathrm{NH}_{3}$ gas streams one at a time. The (0001) sapphire substrates were solventcleaned first, followed by hot-etching in $\mathrm{HCl}-\mathrm{H}_{3} \mathrm{PO}_{4}$ (3:1) solution for $5 \mathrm{~min}$, then rinsed with deionized water, and blow-dried with $\mathrm{N}_{2}$. GaN buffer layers of $200 \AA$ in thickness were deposited at $500^{\circ} \mathrm{C}$ after the substrate was heated at $1050^{\circ} \mathrm{C}$ under $\mathrm{NH}_{3}$ for $1 \mathrm{~min}$ nitridation. A series of $2.0 \mu \mathrm{m}$ thick $\mathrm{GaN}$ films were then deposited in a temperature range $500 \sim 950^{\circ} \mathrm{C}$ with $\mathrm{V} / \mathrm{III}$ ratios of $2000 \sim 5000$.

A Bede Q2a double-crystal X-ray diffractometer was utilized for structural characterization. A Topcon ABT55 scanning electron microscope (SEM) operated at 10 $\mathrm{kV}$ was used to reveal the surface morphology and thickness of the grown films. Photoluminescence (PL) measurements using the $325 \mathrm{~nm}$ excitation of a $\mathrm{He}-\mathrm{Cd}$ laser were carried out to characterize the luminescence properties of the GaN films. Contactless electroreflectance (CER) was used for estimation of the emission energies of the excitons in the GaN films. The transport properties of the as-grown GaN films were characterized by van der Pauw Hall measurements.

\section{Results and discussion}

For $\mathrm{GaN}$ films prepared at low temperatures of $500 \sim 700^{\circ} \mathrm{C}$, the crystallinity of the films is poor with broad DCXRD linewidth. GaN films grown at elevated temperatures without a low temperature $\mathrm{GaN}$ buffer layer tends to result in a rough surface morphology with a (0004) DCXRD linewidth of $10 \sim 20$ arcmin. However, high quality, transparent $\mathrm{GaN}$ films having a smooth morphology were achievable in a temperature range $800 \sim 900^{\circ} \mathrm{C}$ through optimization of the growth parameters like nitridation time, buffer layer thickness,

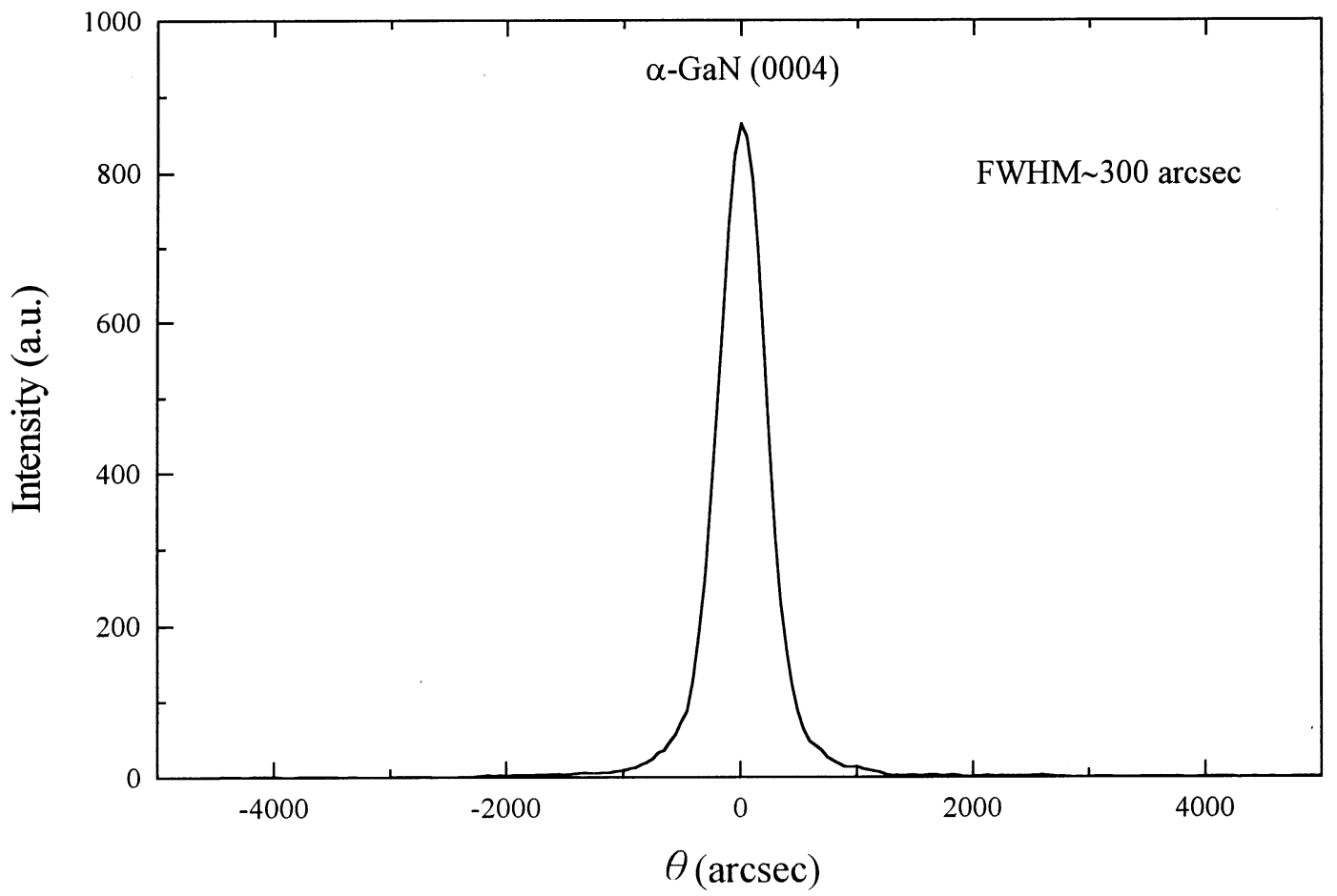

Fig. 2. A typical (0004) DCXRD curve of a GaN film grown at $850^{\circ} \mathrm{C}$. 


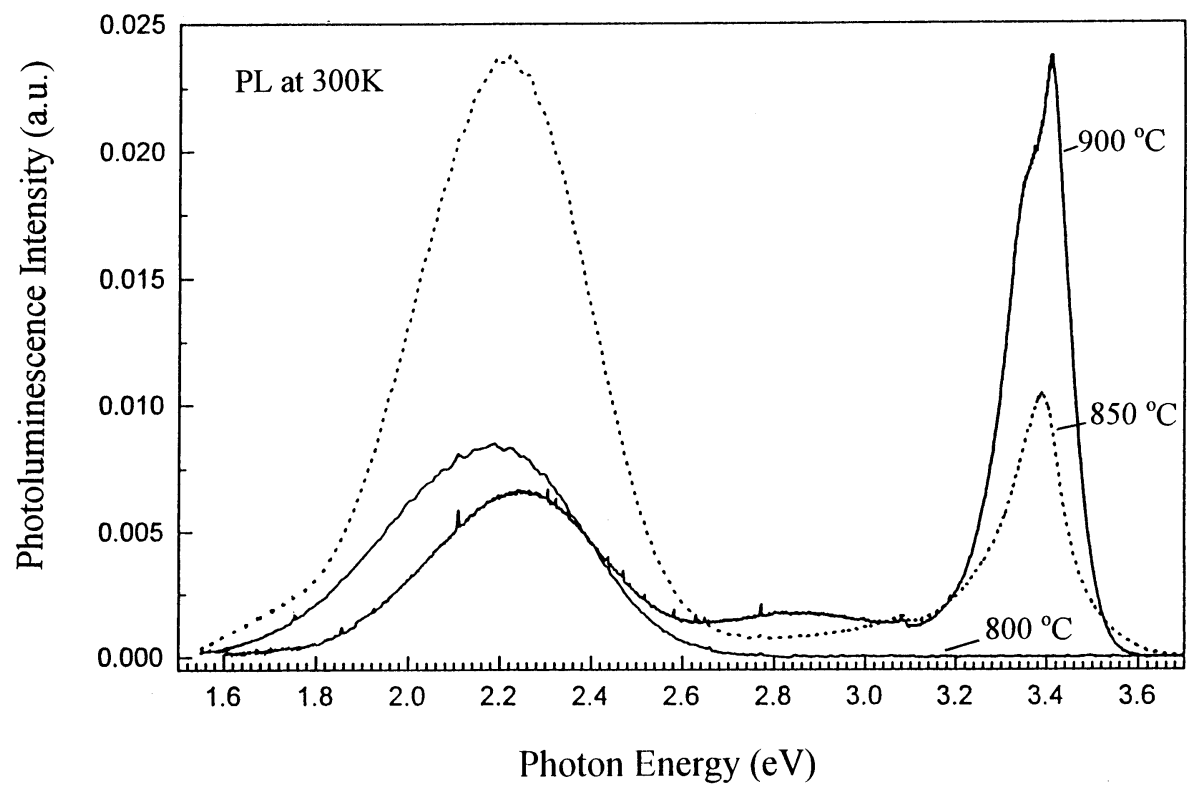

Fig. 3. The RT PL data of GaN films grown at 800,850 and $900^{\circ} \mathrm{C}$, respectively.

buffer layer deposition temperature, growth temperature, and V/III ratio which have been reported as very critical in the growth of high quality GaN by MOCVD $[10,11]$. As-grown films are n-type with room temperature carrier concentrations and mobilities falling in low $10^{18} \sim \operatorname{mid} 10^{19} \mathrm{~cm}^{-3}$ and $20 \sim 50 \mathrm{~cm}^{2} / \mathrm{V}$-sec, respectively. Fig. 1 shows an SEM micrograph of the surface of a $\mathrm{GaN}$ film grown at $800^{\circ} \mathrm{C}$ with a $\mathrm{GaN}$ buffer layer thickness of $200 \AA$ deposited at $500^{\circ} \mathrm{C}$. The micrograph shows a smooth surface morphology which is typical for $\mathrm{GaN}$ films grown at temperatures of this range. A particle in the micrograph is intentionally chosen for focusing purpose. Most of the $\mathrm{GaN}$ films grown at $800 \sim 900^{\circ} \mathrm{C}$ show good crystallinity with the linewidth of (0004) DCXRD falling within $250 \sim 500 \mathrm{arcsec}$. Fig. 2 shows a typical DCXRD curve of a $2.0 \mu \mathrm{m}$ thick $\mathrm{GaN}$ film grown at $850^{\circ} \mathrm{C}$ with a $\mathrm{GaN}$ buffer layer thickness of $200 \AA$ deposited at $500^{\circ} \mathrm{C}$. The full width at half maximum (FWHM) of the (0004) diffraction peak is about 300 arcsec which is comparable to the results reported in the $\mathrm{GaN}$ films grown by other growth techniques [12]. It has been reported that an alternate supply of the reactants is helpful in enhancing the surface velocities of the adatoms on the grown surface [13]. An alternating supply of $\mathrm{TMG}$ and $\mathrm{NH}_{3}$ thus provides higher surface diffusion velocities of the $\mathrm{Ga}$ adatoms to locate themselves at proper atomic sites. Furthermore, growth by alternate supply of reactants is dominated by a surface kinetics limited process rather than a mass transport limited process. In a so called self-limiting process [7], only partially cracked $\mathrm{N}-\mathrm{H}$ radicals instead of atomic nitrogen are required for the accomplishment of adsorption processes. For $\mathrm{NH}_{3}$, the thermal energy for forming partially cracked $\mathrm{N}-\mathrm{H}$ rad- icals is less than that for the formation of atomic nitrogens. Consequently, GaN films of high crystallinity are achievable by an alternating supply of TMG and $\mathrm{NH}_{3}$ at a relatively lower temperature range than that of conventional MOCVD growth.

Increase in growth temperature over the range $800 \sim$ $900^{\circ} \mathrm{C}$ results in apparent reduction in the luminescence intensities of the yellow emissions located near $2.25 \mathrm{eV}$ and enhancement in the luminescence intensity of the near band-to-band emission. Fig. 3 shows the room temperature(RT) PL results of the GaN films prepared at 800,850 and $900^{\circ} \mathrm{C}$, respectively, with the same V/III ratio of 3000 . For the $\mathrm{GaN}$ films grown at $800^{\circ} \mathrm{C}$, the RT PL spectrum shows only yellow luminescence with near band-to-band emission being completely quenched. Increment in growth temperature to $850^{\circ} \mathrm{C}$ tends to enhance near band-to-band emission but the yellow luminescence intensity stays high. For GaN films grown at $900^{\circ} \mathrm{C}$, the RT PL spectrum shows very strong near band-to-band emission with greatly reduced yellow luminescence intensity. A further increase in growth temperature up to $950^{\circ} \mathrm{C}$, however, tends to cause a deterioration of the morphology of the GaN films although the PL properties of the $\mathrm{GaN}$ films prepared at $950^{\circ} \mathrm{C}$ are pretty much the same as those obtained in the samples grown at $900^{\circ} \mathrm{C}$. In this case SEM observations show localized cavities on the surface of $\mathrm{GaN}$ films grown at temperatures higher than $95^{\circ} \mathrm{C}$. The growth temperature increment tends to result in an increase in thermal energy which is helpful in the promotion of surface mobilities of the adatoms and the cracking efficiency of $\mathrm{NH}_{3}$, however, thermal energy at this temperature range may also result in considerable desorption of the $\mathrm{Ga}$ and $\mathrm{N}$ adatoms at the grown 


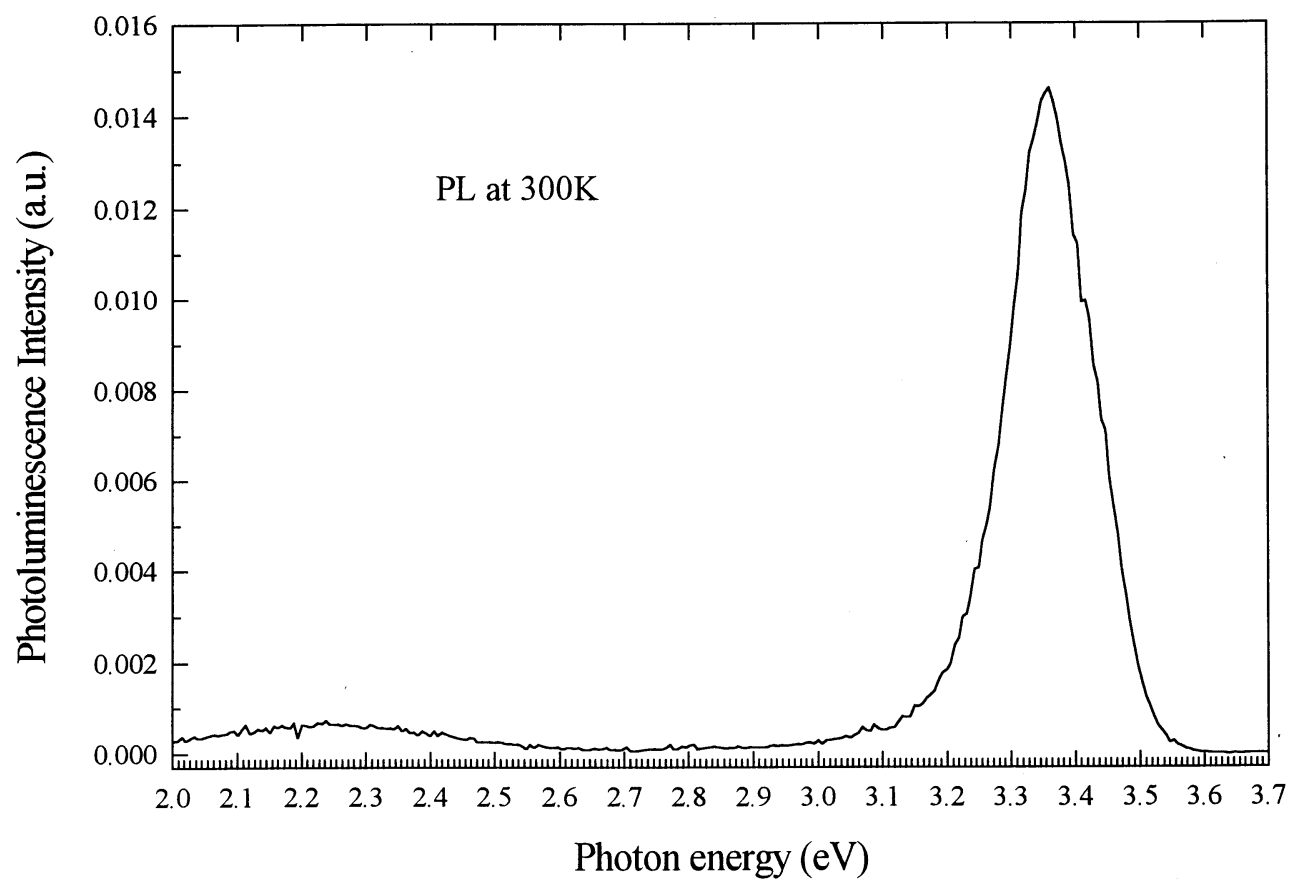

Fig. 4. Typical RT PL spectrum of the high quality GaN films.

surface. In particular, the desorption rate of $\mathrm{Ga}$ becomes prominent at elevated temperatures if the replenishment of reactive $\mathrm{N}-\mathrm{H}$ radicals is insufficient. Thus, an optimized growth temperature is essential for the growth of high quality $\mathrm{GaN}$ film at a given V/III ratio. Based upon the PL results shown in Fig. 3, at the temperatures of $800 \sim 850^{\circ} \mathrm{C}$ and a V/III ratio of 3000 , the amount of reactive $\mathrm{N}-\mathrm{H}$ radicals may not be high enough to support sufficient overpressure on the grown surface due to the insufficient cracking efficiency of $\mathrm{NH}_{3}$ at this temperature range. As a result, defects like $\mathrm{Ga}$ vacancies as well as complexes between $\mathrm{Ga}$ vacancies and impurities may easily be created at this temperature range. These defects have been reported to be responsible for the yellow luminescence near $2.25 \mathrm{eV}$ $[14,15]$. The observed yellow luminescence dominant PL spectra of the $\mathrm{GaN}$ films prepared at $800 \sim 850^{\circ} \mathrm{C}$ can thus be attributed to the high density of states of these defects. It is known that high quality $\mathrm{GaN}$ films can only be achieved by very high $\mathrm{V} / \mathrm{III}$ ratios at temperatures higher than $1000^{\circ} \mathrm{C}$ by the MOCVD process because the gas phase decomposition of $\mathrm{NH}_{3}$ occurs only at very high temperatures [16]. Similarly, a sufficient supply of the reactive $\mathrm{N}-\mathrm{H}$ radicals is crucial for the growth of high quality $\mathrm{GaN}$ films in this study. For a given $\mathrm{V} / \mathrm{III}$ ratio of 3000 , growth temperature increment from 800 to $900^{\circ} \mathrm{C}$ allows the provision of more reactive $\mathrm{N}-\mathrm{H}$ radicals which are beneficial in reducing the density of the states of the defects related to $\mathrm{Ga}$ vacancies. This gives an interpretation for the change in PL spectra from yellow luminescence dominant to near band-to-band emission dominant when growth temper- ature increases from 800 to $900^{\circ} \mathrm{C}$. A similar tendency was found in the GaN films grown at $\mathrm{V} / \mathrm{III}$ ratios higher than 3000. Fig. 4 shows a RT PL of a GaN film prepared at $900^{\circ} \mathrm{C}$ with a V/III ratio of 5000 . Note that the PL intensity ratio of the near band edge emission to the yellow luminescence is more than one order of magnitude.

Fig. 5 shows the CER spectra of the $\mathrm{GaN}$ films grown at $900^{\circ} \mathrm{C}$. The transition energies of free excitons (FX) [17] were estimated by fitting the curves to the first derivative of a Lorentzian lineshape function form [18]. As indicated by the arrows in Fig. 5, blue-shift in the excitonic emission energies of A excitons from 3.422 to $3.484 \mathrm{eV}$ and $\mathrm{B}$ excitons from 3.429 to $3.492 \mathrm{eV}$ has

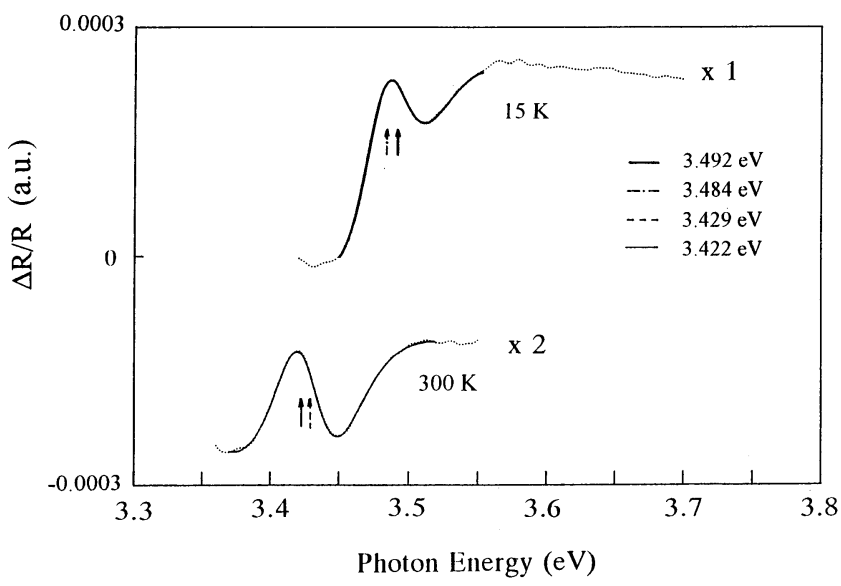

Fig. 5. The $300 \mathrm{~K}$ and $15 \mathrm{~K}$ CER spectra of a GaN film grown at $900^{\circ} \mathrm{C}$. 


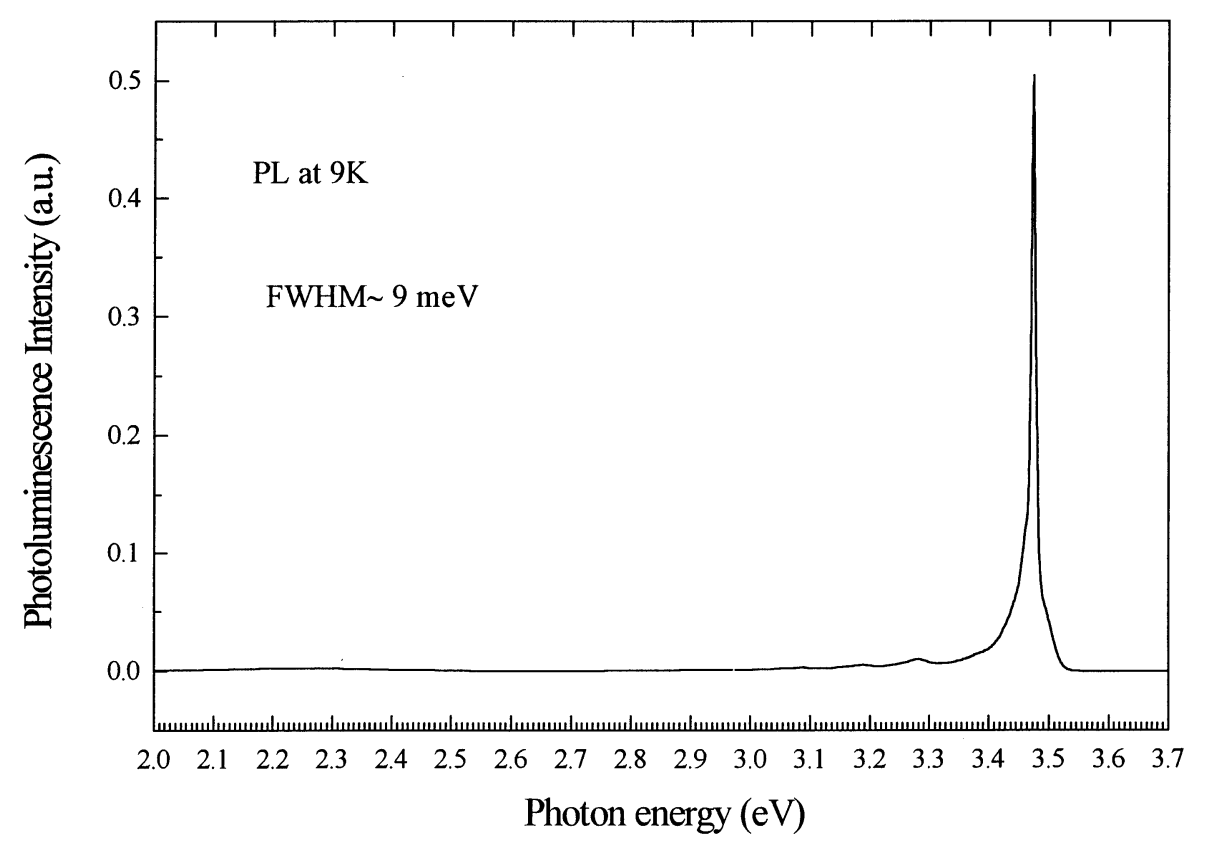

Fig. 6. A PL spectrum of the best $\mathrm{GaN}$ films grown at $900^{\circ} \mathrm{C}$ with a V/III ratio of 5000 .

been observed as the measurement temperature reduces from RT to $15 \mathrm{~K}$. This result is in good agreement with the reported excitonic transition energies of $\mathrm{A}$ and $\mathrm{B}$ FXs in GaN films grown by MOCVD on (0001) sapphire substrates [17,19]. A biaxially compressive strain of $0.04 \%$ for the GaN films grown in this study is estimated accordingly. It is not certain why the signal of the transition energy of $\mathrm{C}$ excitons is absent in the $15 \mathrm{~K}$ CER spectrum in Fig. 5. Previous report shows that the binding energy of $\mathrm{C}$ excitons is lower than that of $\mathrm{A}$ and $\mathrm{B}$ excitons [17]. Nevertheless, the difference in binding energies between $\mathrm{A} / \mathrm{B}$ and $\mathrm{C}$ excitons is not prominent. Thus, the binding energy difference can only partly explain the CER result even if $\mathrm{C}$ excitons are dissociated predominantly due to the high background of n-type dopants of the order of $10^{18} \sim 10^{19} \mathrm{~cm}^{-3}$ in the as-grown $\mathrm{GaN}$ films. However, it can not explain the complete disappearance of $\mathrm{C}$ excitons in the $15 \mathrm{~K}$ CER spectrum. More work is required to elucidate this issue.

It appears that a further increment in V/III ratio is helpful to increase the PL intensity ratio of the near band edge luminescence to the yellow emission. A comparison of the RT PL data of Figs. 3 and 4 shows that the intensity ratio of near band edge luminescence to yellow emission has increased from a ratio of 4 for $\mathrm{GaN}$ films grown at $900^{\circ} \mathrm{C}$ with a V/III ratio of 3000 (as shown in Fig. 3) to a ratio of 20 for $\mathrm{GaN}$ films prepared at $900^{\circ} \mathrm{C}$ with a V/III ratio of 5000. It is believed that $\mathrm{NH}_{3}$ overpressure helps to cut down the density of yellow luminescence defects. Fig.
6 shows the $9 \mathrm{~K}$ PL spectrum of a $\mathrm{GaN}$ film grown at $900^{\circ} \mathrm{C}$ with a $\mathrm{V} / \mathrm{III}$ ratio of 5000 . Note that the 9 $\mathrm{K}$ PL intensity of the near band-to-band emission is very strong with a linewidth as narrow as $9 \mathrm{meV}$ and the yellow luminescence is so weak that it can hardly be detected. A careful inspection of the $9 \mathrm{~K}$ PL spectrum in Fig. 6 shows that the emission energy of the primary peak is about $3.475 \mathrm{eV}$ which has been identified as the emission of the A free excitons bound to neutral donors associated with nitrogen vacancies $[17,20]$.

\section{Conclusion}

In conclusion, high crystalline quality $\mathrm{GaN}$ films were achieved on (0001) sapphire substrates in the range $800 \sim 900^{\circ} \mathrm{C}$ by an alternate supply of $\mathrm{TMG}$ and $\mathrm{NH}_{3}$ with a thin $\mathrm{GaN}$ buffer layer predeposited at $500^{\circ} \mathrm{C}$. The structural and optical properties of the GaN films grown in this investigation are comparable to those obtained in the GaN films grown by conventional techniques. The best $\mathrm{GaN}$ films were achieved at $900^{\circ} \mathrm{C}$ with a $9 \mathrm{~K} \mathrm{PL}$ linewidth of the $3.475 \mathrm{eV}$ emission as narrow as $9 \mathrm{meV}$. The preparation of high quality $\mathrm{GaN}$ films at relatively lower temperatures than that reported in the MOCVD growth has been attributed to the migration enhancement of the $\mathrm{Ga}$ adatoms on the grown surface and the easy access of cracked $\mathrm{N}-\mathrm{H}$ radicals for the growth process implemented in current investigation. 


\section{Acknowledgements}

This work was supported in part by the National Science Council of Taiwan with contract numbers NSC 83-0404-E-035-001 and NSC 84-2215-E-035-003. The authors would like to thank Professor Y.S. Huang's group at the Electronic Engineering Department, National Taiwan University of Science and Technology, Taipei, Taiwan. and Dr P.T. Chang's group at the United Epitaxy Company, Hsinchu, Taiwan, for assistance in the CER and DCXRD measurements.

\section{References}

[1] S. Nakamura, M. Senoh, N. Iwasa, S. Nagahama, Jpn. J. Appl. Phys. 34 (1995) L797.

[2] S. Nakamura, M. Senoh, S. Nagahama, et al., Appl. Phys. Lett. 70 (1997) 1417.

[3] X.H. Wu, P. Fini, S. Keller, et al., Jpn. J. Appl. Phys. 35 (1996) L1648.

[4] Q. Zhu, A. Botchkarev, W. Kim, et al., Appl. Phys. Lett. 68 (1996) 1141.

[5] K. Naniwae, S. Itoh, H. Amano, K. Itoh, K. Hiramastu, I. Akasaki, J. Cryst. Growth 99 (1990) 381.
[6] S.D. Lester, F.A. Ponce, M. G. Craford, D.A. Steigerwald, Appl. Phys. Lett. 66 (1995) 1249.

[7] S.P. DenBaars, P.D. Dapkus, J. Crystal Growth 98 (1989) 195.

[8] J.R. Gong, D. Jung, N.A. El-Masry, S.M. Bedair, Appl. Phys. Lett. 57 (1990) 400.

[9] H. Tsuchiya, M. Akamatsu, M. Ishida, F. Hasegawa, Jpn. J. Appl. Phys. 35 (1996) L748.

[10] N. Grandjean, J. Massies, M. Leroux, Appl. Phys. Lett. 69 (1996) 2071.

[11] J.N. Kuznia, M. A. Khan, D.T. Olson, R. Kaplan, J. Freitas, J. Appl. Phys. 73 (1993) 4700.

[12] S. Nakamura, Y. Harada, M. Seno, Appl. Phys. Lett. 58 (1991) 2021.

[13] Y. Horikoshi, M. Kawashima, H. Yamaguchi, Jpn. J. Appl. Phys. 25 (1986) L868.

[14] T. Suski, P. Perlin, H. Teisseyre, et al., Appl. Phys. Lett. 67 (1995) 2188.

[15] J. Neugebauer, C.G. Van de Walle, Appl. Phys. Lett. 69 (1996) 503.

[16] A. Thon, T.F. Kuech, Appl. Phys. Lett. 69 (1996) 55.

[17] G.D. Chen, M. Smith, J.Y. Lin, et al., Appl. Phys. Lett. 68 (1996) 2784.

[18] D.E. Aspnes, in: T.S Moss (Ed.), 'Handbook on Semiconductors, vol. 2, North-Holland, Amsterdam, 1980, p. 109.

[19] S. Chichibu, A. Shikanai, T. Azuhata, et al., Appl. Phys. Lett. 68 (1996) 3766.

[20] W. Rieger, R. Dimitrov, D. Brunner, E. Rohrer, O. Ambacher, M. Stutzmann, Phys. Rev. B 54 (1996) 17596. 